\title{
A Reformulation of the Hausman Test for Regression Models with Pooled Cross-Section-Time-Series Data
}

\author{
Seung Chan Ahn* \\ Arizona State University, Tempe, AZ 85287, USA \\ Stuart Low \\ Arizona State University, Tempe, AZ 85287, USA
}

\begin{abstract}
A Hausman test has been typically used to determine the consistency of the GLS estimator in static models with pooled cross-section-time-series data. Based on a GMM approach, we reformulate the Hausman test and find that it incorporates and tests only a limited set of moment restrictions. We also consider an alternative GMM statistic incorporating additional restrictions, which has power toward additional sources of model misspecification. Our Monte Carlo experiments demonstrate that while both the Hausman test and the alternative have good power detecting endogenous regressors, the alternative dominates if coefficients of regressors are nonstationary.
\end{abstract}

Key Words: Hausman Test; GMM test; Pooled-cross-section-time-series data; nonstationary coefficients

JEL classification: $\mathrm{C} 23$

\footnotetext{
* Corresponding author, Department of Economics, Arizona State University, Tempe, AZ 85287-3806, USA. Phone: (602) 965-6574; FAX: (602) 965-0748.
} 


\section{Introduction*}

Use of pooled cross-section-time-series (CS-TS) regression methods has become increasingly common as availability of longitudinal data sets has grown. The primary estimation methods for static models are the within-group and the generalized least squares (GLS) estimators. Central to the appropriate choice of estimator is a specification test for the presence of endogenous regressors. ${ }^{1}$ The Hausman statistic (1978) has been commonly used in the literature for testing the consistency of the GLS estimator (e.g., Hausman and Taylor, 1981; Cornwell and Rupert, 1988; or Baltagi and Khanti-Akom, 1990).

This paper focuses on one simple generalization of the Hausman test, which is previously considered by Arellano (1993). The Hausman statistic incorporates and tests a specific set of moment restrictions implying that individual means of the time-varying regressors are exogenous. Our alternative GMM statistic, which is equivalent to Arellano's Wald test, incorporates a broader set of restrictions reflecting that each of the time-varying regressors is exogenous. This alternative test performs well in our Monte Carlo experiments, where it has good power to detect nonstationary coefficients of regressors which the Hausman test often fails to do, while both tests share roughly the same power detecting correlation

\footnotetext{
* The authors gratefully acknowledge the financial support of the College of Business and Dean's Council of 100 at Arizona State University. We would also like to thank the editor and two anonymous referees for many helpful comments on a previous version of this paper. All errors are our own.

${ }^{1}$ We use "endogenous" in the sense that regressors may be correlated with unobservable individual effects.
} 
between individual effects and regressors.

This paper is organized as follows. In section 2, we develop alternative GMM tests and examine their relationship to the Hausman test typically utilized. In section 3 , we consider the GMM test of the Arellano-type moment restrictions and its power properties. Our Monte Carlo simulations are contained in Section 4. The final section contains our conclusions.

\section{GMM Tests of the Random Effects Specification}

In this section, we review the basic CS-TS regression model and the Hausman test for a random effects specification, and then develop alternative GMM tests. The model we consider is given:

$$
\begin{aligned}
y_{i t} & =X_{i t} \beta+Z_{i} \gamma+u_{i t} ; u_{i t}=\alpha_{i}+\epsilon_{i t}, \\
i & =1, \ldots, N ; t=1, \ldots, T
\end{aligned}
$$

where i denotes cross-sectional (individual) observations and tenotes time. In (1), $\mathrm{X}_{\mathrm{it}}$ contains $\mathrm{k}$ time-varying regressors, $\mathrm{Z}_{\mathrm{i}}$ contains $\mathrm{g}$ time-invariant regressors, and the error $\mathrm{u}_{\mathrm{it}}$ contains a time-invariant individual effect $\alpha_{\mathrm{i}}$ and random noise $\varepsilon_{\mathrm{it}}$. We consider the empirically relevant case of a large number of individuals and a small number of time series, so usual asymptotic properties of our tests apply as $\mathrm{N} \rightarrow \infty$ at fixed $\mathrm{T}$.

We assume that the observations are distributed independently across different $\mathrm{i}$, and that the $\varepsilon_{\mathrm{it}}$ are independently and identically distributed (i.i.d.) with $\operatorname{var}\left(\varepsilon_{\mathrm{it}}\right)=\sigma_{\varepsilon}^{2}$, for any $\mathrm{i}$ and t. We further assume that $\alpha_{i}, X_{i 1}, \ldots, X_{i T}$ and $Z_{i}$ are strictly exogenous with respect to $\varepsilon_{\mathrm{it}}$, for any $\mathrm{i}$; that is, $\mathrm{E}\left(\varepsilon_{\mathrm{it}} \mid \alpha_{\mathrm{i}}, \mathrm{X}_{\mathrm{i} 1}, \ldots, \mathrm{X}_{\mathrm{iT}}, \mathrm{Z}_{\mathrm{i}}\right)=0$. This latter assumption rules out the cases 
in which the set of regressors includes lagged dependent variables or predetermined regressors.

Data vectors and matrices are created by stacking the observations first by individual and then by time. For example,

$$
y=\left[y_{11}, \ldots, y_{1 T} ; \ldots ; y_{N I}, \ldots, y_{N T}\right]^{\prime}
$$

With this convention the model in matrix form is:

$$
y=X \beta+Z \gamma+u=W \delta+u
$$

where $\mathrm{W}=[\mathrm{X}, \mathrm{Z}], \delta=\left[\beta^{\prime}, \gamma^{\prime}\right]^{\prime}$, and $\mathrm{u}=\alpha+\varepsilon$.

We adopt the standard notation for projections. For any matrix $\mathrm{A}$, let $\mathrm{P}(\mathrm{A})$ be the projection onto the column space of $A$, so that $P(A)=A\left(A^{\prime} A\right)^{-1} A^{\prime}$, and let $Q(A)=I-P(A)$. If we specify $\ell_{T}$ as a $T \times 1$ vector of ones, we may define:

$$
V=I_{N} \otimes \ell_{T} ; P_{V}=P(V)=I_{N} \otimes\left(\ell_{T} \ell_{T}^{\prime} / T\right) ; Q_{V}=I_{N T}-P_{V}
$$

where $\mathrm{V}$ is a matrix of individual dummy variables, $\mathrm{P}_{\mathrm{V}}$ converts an $\mathrm{NT} \times 1$ vector ordered as in (2) into a vector of individual means, and $\mathrm{Q}_{\mathrm{V}}$ converts an $\mathrm{NT} \times 1$ vector into deviations from individual means.

When the regressors are correlated with the individual effects, both the OLS and GLS estimators are biased and inconsistent. This problem has been traditionally addressed by the use of the within-group estimator (OLS on data transformed into deviations from individual means): $\hat{\beta}_{\mathrm{W}}=\left(\mathrm{X}^{\prime} \mathrm{Q}_{\mathrm{V}} \mathrm{X}\right)^{-1} \mathrm{X}^{\prime} \mathrm{Q}_{\mathrm{V}} \mathrm{y}$. Although this method provides a consistent estimate of $\beta$, a serious defect is the inability to estimate $\gamma$, the impact of time-invariant regressors.

When the $\alpha_{i}$ are random and uncorrelated with the regressors, both $\beta$ and $\gamma$ can be 
consistently estimated. Specifically, assume that $\operatorname{var}\left(\alpha_{\mathrm{i}} \mid \mathrm{X}_{\mathrm{i} 1}, \ldots, \mathrm{X}_{\mathrm{iT}}, \mathrm{Z}_{\mathrm{i}}\right)=\sigma_{\alpha}^{2}$, for any $\mathrm{i}$, and that the following hypothesis holds:

$$
H_{o}: E\left(\alpha_{i} \mid X_{i 1}, \ldots, X_{i T}, Z_{i}\right)=0
$$

In this case, a simple but consistent estimator is the between-group estimator: $\hat{\delta}_{\mathrm{B}}=\left[\hat{\beta}_{\mathrm{B}}{ }^{\prime}, \hat{\gamma}_{\mathrm{B}}{ }^{\prime}\right]^{\prime}$ $=\left(\mathrm{W}^{\prime} \mathrm{P}_{\mathrm{V}} \mathrm{W}\right)^{-1} \mathrm{~W}^{\prime} \mathrm{P}_{\mathrm{V}} \mathrm{y}$. However, as Balestra and Nerlove (1966) demonstrate, an efficient estimator can be obtained using GLS. Note that:

$$
\operatorname{Cov}(u)=T \sigma_{\alpha}^{2} P_{V}+\sigma_{\epsilon}^{2} I_{N T}=\sigma_{\epsilon}^{2}\left(\theta^{-2} P_{V}+Q_{V}\right) \equiv \sigma_{\epsilon}^{2} \Omega
$$

where $\theta=\left(\sigma_{\varepsilon}^{2} / \sigma_{\mathrm{B}}^{2}\right)^{1 / 2}$ and $\sigma_{\mathrm{B}}^{2}=\mathrm{T} \sigma_{\alpha}^{2}+\sigma_{\varepsilon}^{2}$. The GLS estimator is given:

$$
\hat{\delta}_{G}=\left[\hat{\beta}_{G}^{\prime}, \hat{\gamma}_{G}^{\prime}\right]^{\prime}=\left(W^{\prime} \Omega^{-1} W\right)^{-1} W^{\prime} \Omega^{-1} y
$$

which can be obtained by OLS on:

$$
\Omega^{-1 / 2} y=\Omega^{-1 / 2} W \delta+\Omega^{-1 / 2} u,
$$

where $\Omega^{-1 / 2}=\theta \mathrm{P}_{\mathrm{V}}+\mathrm{Q}_{\mathrm{V}}$. For notational convenience, we assume that $\sigma_{\varepsilon}^{2}$ and $\sigma_{\mathrm{B}}^{2}$ are known, while in practice they must be estimated. The conventional estimates are given:

$$
\hat{\sigma}_{\epsilon}^{2}=e_{W}^{\prime} e_{W} /[N(T-1)] ; \hat{\sigma}_{B}^{2}=e_{B}^{\prime} e_{B} / N ; \hat{\theta}=\left(\hat{\sigma}_{\epsilon}^{2} / \hat{\sigma}_{B}^{2}\right)^{1 / 2}
$$

where $\mathrm{e}_{\mathrm{W}}=\mathrm{Q}_{\mathrm{V}}\left(\mathrm{y}-\mathrm{X} \hat{\beta}_{\mathrm{W}}\right)$ and $\mathrm{e}_{\mathrm{B}}=\mathrm{P}_{\mathrm{V}}\left(\mathrm{y}-\mathrm{W} \hat{\delta}_{\mathrm{B}}\right)$.

The appropriateness of between-group and GLS estimation requires that the regressors are uncorrelated with the effects, i.e., $\mathrm{H}_{\mathrm{o}}$ must hold. Traditionally a Hausman test (1978) has been utilized to test $H_{o}$. The Hausman test is based on differences between $\beta_{\mathrm{W}}$ and $\beta_{\mathrm{G}}$ : 


$$
H_{N}=\left(\hat{\beta}_{W}-\hat{\beta}_{G}\right)^{\prime}\left[\operatorname{Cov}\left(\hat{\beta}_{W}\right)-\operatorname{Cov}\left(\hat{\boldsymbol{\beta}}_{G}\right)\right]^{-1}\left(\hat{\boldsymbol{\beta}}_{W}-\hat{\boldsymbol{\beta}}_{G}\right),
$$

which, under $\mathrm{H}_{\mathrm{o}}$, is asymptotically chi-squared with $\mathrm{k}$ degrees of freedom. Hausman and Taylor (1981, Proposition 2.2) show that alternative forms of $H_{N}$ can be given in terms of ( $\beta_{G}$ $\left.-\hat{\beta}_{\mathrm{B}}\right)$ or $\left(\hat{\beta}_{\mathrm{w}}-\hat{\beta}_{\mathrm{B}}\right)$.

We now consider alternative tests of $\mathrm{H}_{\mathrm{o}}$ under GMM framework. We define:

$$
B=\left[Q_{V} X, Z, S\right],
$$

where $\mathrm{S}$ is a $\mathrm{TN} \times \mathrm{q}(\mathrm{q} \geq \mathrm{k})$ matrix whose columns are functions of $\mathrm{X}$ and $\mathrm{Z}$ so that under $\mathrm{H}_{\mathrm{o}}, \mathrm{S}$ is uncorrelated with $\mathrm{u}$. We assume that rank of B equals its number of columns. We further assume that:

(i) $P_{V} X$ is in the column space of $S$, i.e., $P(S) P_{V} X=P_{V} X$.

(ii) All of the columns of $\mathrm{S}$ are in either $\mathrm{Q}_{\mathrm{V}}$ or $\mathrm{P}_{\mathrm{V}}$ spaces. Assumption (ii) is unnecessary for our GMM tests, but is assumed for convenience. Under assumptions (i) and (ii), it is straightforward to show ${ }^{2}$ :

$$
P(B)=P\left(\Omega^{-1 / 2} W, S\right)=P\left(\Omega^{-1 / 2} W, \Omega^{-1 / 2} S\right) .
$$

Under $\mathrm{H}_{0}$, the following overidentifying moment conditions are implied:

$$
E\left[B^{\prime} \Omega^{-1 / 2}(y-W \delta)\right]=0 .
$$

The 2SLS estimator of $\delta$, which is optimal among all GMM estimators based on the moment conditions in (11), solves the problem:

\footnotetext{
${ }^{2}$ The first equality requires assumption (i) and the second requires both (i) and (ii).
} 


$$
\begin{aligned}
\min _{\delta} J(\delta, B) & \equiv(y-W \delta)^{\prime} \Omega^{-1 / 2} P(B) \Omega^{-1 / 2}(y-W \delta) / \sigma_{\epsilon}^{2} \\
& =(y-W \delta)^{\prime} \Omega^{-1 / 2} P\left(\Omega^{-1 / 2} W, \Omega^{-1 / 2} S\right) \Omega^{-1 / 2}(y-W \delta) / \sigma_{\epsilon}^{2} .
\end{aligned}
$$

Clearly, the 2SLS estimator from (14) equals $\delta_{\mathrm{G}}$ in (7). Therefore, Hansen's (1982) GMM statistic for testing the overidentifying orthogonality condition (13) is defined by:

$$
J_{N}(B) \equiv J\left(\hat{\delta}_{G}, B\right)=e_{G}^{\prime} P(B) e_{G} / \sigma_{\epsilon}^{2},
$$

where $\mathrm{e}_{\mathrm{G}}=\Omega^{-1 / 2}\left(\mathrm{y}-\mathrm{W} \hat{\delta}_{\mathrm{G}}\right)$ is the vector of GLS residuals. Under $\mathrm{H}_{0}, \mathrm{~J}_{\mathrm{N}}(\mathrm{B})$ is asymptotically chisquared with $q$ degrees of freedom. If we replace $\sigma_{\varepsilon}^{2}$ by $\mathrm{e}_{\mathrm{G}}{ }^{\prime} \mathrm{e}_{\mathrm{G}} /(\mathrm{TN}), \mathrm{J}_{\mathrm{N}}(\mathrm{B})$ can be obtained by multiplying the number of observations $\left(\mathrm{TN}\right.$ ) and the uncentered $\mathrm{R}^{2}$ (or $\mathrm{R}^{2}$ if the model includes an overall intercept term) from a regression of $\mathrm{e}_{\mathrm{G}}$ on $\mathrm{Q}_{\mathrm{V}} \mathrm{X}, \mathrm{Z}$ and $\mathrm{S}$.

Several remarks on the GMM statistic $\mathrm{J}_{\mathrm{N}}(\mathrm{B})$ are worth noting. The 2SLS estimator of the model in (8) using $\left[\Omega^{-1 / 2} \mathrm{~W}, \Omega^{-1 / 2} \mathrm{~S}\right]$ as instruments is equivalent to the efficient GLS estimator. Therefore, the instruments in $\mathrm{S}$ are redundant for the efficient estimation of $\delta$. However, these additional instruments are relevant for the construction of an appropriate test statistic, since any evidence of correlation between these additional instruments and the error implies a violation of $\mathrm{H}_{0}$, the assumption which insures consistency of GLS estimates.

Another important property of $\mathrm{J}_{\mathrm{N}}(\mathrm{B})$ can be found by considering the following auxiliary regression model:

$$
y=W \delta+S \phi+v ; v=u-S \phi .
$$

Mundlak (1978) has considered GLS estimation of the model in (16) with $S=P_{V} X$. Note that $\phi=0$ when $H_{o}$ holds. Substituting equality (12) into $J_{N}(B)$ in (15), we can see that $J_{N}(B)$ equals the Lagrangean Multiplier (LM) statistic of the restriction $\phi=0$ from restricted GLS 
estimates of model (16). Further, the fact that LM and Wald tests in a linear regression model are equivalent implies that $\mathrm{J}_{\mathrm{N}}(\mathrm{B})$ also should equal the Wald statistic of the restriction $\phi=0$ from unrestricted GLS estimates, if the same estimates of $\theta$ and $\sigma_{\varepsilon}^{2}$ are used.

There are numerous possible GMM tests depending on the choice of S. However, any GMM test of the form $\mathrm{J}_{\mathrm{N}}(\mathrm{B})$ can be regarded as a generalization of the Hausman test. To see why, let $\xi=\left[\beta^{\prime}, \gamma^{\prime}, \phi^{\prime}\right]^{\prime}$; and let $\xi_{\mathrm{H}}$ be the unrestricted GLS estimator of model (16) with $S=$ $\mathrm{P}_{\mathrm{V}} \mathrm{X}$. By Mundlak (1978), we have:

$$
\hat{\xi}_{H} \equiv\left[\hat{\beta}_{H}^{\prime}, \hat{\gamma}_{H}^{\prime}, \hat{\Phi}_{H}^{\prime}\right]^{\prime}=\left[\hat{\beta}_{W}^{\prime}, \hat{\gamma}_{B}^{\prime},\left(\hat{\beta}_{B}-\hat{\beta}_{W}\right)^{\prime}\right]^{\prime}
$$

Then, Proposition 2.2 of Hausman and Taylor (1981) applies, and the Wald test is equivalent to the Hausman test. Therefore, we obtain the following result:

Proposition 1. Let $B_{H}=\left[Q_{V} X, Z, P_{V} X\right]$. Then, $H_{N}=J_{N}\left(B_{H}\right)$.

Proposition 1 and the form of $\mathrm{J}_{\mathrm{N}}\left(\mathrm{B}_{\mathrm{H}}\right)$ imply that $\mathrm{H}_{\mathrm{N}}$ incorporates and tests a specific set of orthogonality conditions: individual means of time-varying regressors are uncorrelated with the individual effects, i.e., $\mathrm{E}\left(\overline{\mathrm{X}}_{\mathrm{i}}^{\prime} \overline{\mathrm{u}}_{\mathrm{i}}\right)=\mathrm{E}\left(\overline{\mathrm{X}}_{\mathrm{i}}^{\prime} \alpha_{\mathrm{i}}\right)=0$, where $\overline{\mathrm{X}}_{\mathrm{i}}$ and $\overline{\mathrm{u}}_{\mathrm{i}}$ are the individual means of $\mathrm{X}_{\mathrm{it}}$ and $\mathrm{u}_{\mathrm{i}}$, respectively. In general, $\mathrm{H}_{\mathrm{o}}$ may imply other orthogonality conditions. For tests of additional moment restrictions, researchers may formulate $J_{N}(B)$ by including additional instruments in B.

\section{An Alternative GMM Test}

In the previous section, we have developed GMM tests of the random effects 
specification. In practice, which variables to include in $\mathrm{S}$ (and B) is an important issue. In this section we confine our attention to a simple alternative to $\mathrm{H}_{\mathrm{N}}$, which, we believe, is of practical use.

As Arellano (1993) and Amemiya and MaCurdy (1986) have noted, the hypothesis $\mathrm{H}_{\mathrm{o}}$ may imply that each $\mathrm{X}_{\mathrm{it}}$ is uncorrelated with $\alpha_{\mathrm{i}}$, not simply that $\overline{\mathrm{X}}_{\mathrm{i}}$ is uncorrelated with $\alpha_{\mathrm{i}}$. Testing these conditions is equivalent to testing the orthogonality conditions:

$$
E\left(S_{i}^{*^{\prime}} \bar{u}_{i}\right)=E\left(S_{i}^{*^{\prime}} \alpha_{i}\right)=0
$$

where $\mathrm{S}_{\mathrm{i}}^{*}=\left[\mathrm{X}_{\mathrm{i} 1}, \ldots, \mathrm{X}_{\mathrm{iT}}\right]$. For a GMM test of condition (18), define:

$$
S^{*}=\left[S_{1}^{*^{\prime}}, \ldots, S_{1}^{*^{\prime}} ; \ldots ; S_{N}^{*^{\prime}}, \ldots, S_{N}^{*^{\prime}}\right]^{\prime}
$$

and note that $\mathrm{P}\left(\mathrm{S}^{*}\right) \mathrm{P}_{\mathrm{V}} \mathrm{X}=\mathrm{P}_{\mathrm{V}} \mathrm{X}$ and $\mathrm{P}_{\mathrm{V}} \mathrm{S}^{*}=\mathrm{S}^{*}$. With the choice of $\mathrm{B}^{*}=\left[\mathrm{Q}_{\mathrm{V}} \mathrm{X}, \mathrm{Z}, \mathrm{S}^{*}\right]$, our GMM statistic becomes:

$$
J_{N}^{*} \equiv J_{N}\left(B^{*}\right)=e_{G}^{\prime} P\left(Q_{V} X, Z, S^{*}\right) e_{G} / \sigma_{\epsilon}^{2}
$$

which is, under $\mathrm{H}_{\mathrm{o}}$, asymptotically chi-squared with Tk degrees of freedom.

Arellano (1993) proposes a Wald test of condition (18) which takes the form of a Chow test under heteroskedasticity, and which we refer to as $\mathrm{A}_{\mathrm{N}}$. There are many possible ways to compute $A_{N} \cdot{ }^{3}$ Among them, one means to obtain $A_{N}$ is the use of unrestricted GLS estimates of model (16) with $S=S^{*}$. After some algebra, it can be shown that $A_{N}$ compares with the Wald statistic of the restriction $\phi=0$. Therefore, by an argument similar to that

\footnotetext{
${ }^{3}$ We are thankful to two anonymous referees and the editor for pointing out the possible link between $\mathrm{J}_{\mathrm{N}}^{*}$ and $\mathrm{A}_{\mathrm{N}}$.
} 
underlying Proposition 1 , we can show that $J_{N}^{*}=A_{N}$, if the same estimates of $\Omega$ and $\sigma_{\varepsilon}^{2}$ are used for both $\mathrm{J}_{\mathrm{N}}^{*}$ and $\mathrm{A}_{\mathrm{N}}$. The properties of $\mathrm{J}_{\mathrm{N}}^{*}$ and $\mathrm{A}_{\mathrm{N}}$ may be affected if different estimates are used to form them. However, the difference between the two statistics is asymptotically negligible.

In general, there is no a priori reason to believe that $J_{N}^{*}\left(\right.$ or $\left.A_{N}\right)$ will have better power than $\mathrm{H}_{\mathrm{N}}$ if endogeneity of regressors is the only source generating inconsistent GLS estimates. However, under other possible forms of misspecification, $\mathrm{J}_{\mathrm{N}}^{*}$ may be more powerful than $\mathrm{H}_{\mathrm{N}}$. The implicit assumption behind the use of $\mathrm{H}_{\mathrm{N}}$ is that the presence of some endogenous regressors causes a bias in $\beta_{\mathrm{G}}$ but not in $\beta_{\mathrm{W}}$, as in Hausman (1978). Under this assumption, any significant difference between $\beta_{\mathrm{G}}$ and $\beta_{\mathrm{W}}$ implies rejection of $\mathrm{H}_{\mathrm{o}}$ in favor of within estimation. If, on the other hand, both $\hat{\beta}_{\mathrm{w}}$ and $\hat{\beta}_{\mathrm{G}}$ are inconsistent and biased in the same direction under some alternative specification, $\mathrm{H}_{\mathrm{N}}$ may have low power toward such an alternative, while $\mathrm{J}_{\mathrm{N}}^{*}$ may maintain desirable power properties.

In order to examine the power of $\mathrm{J}_{\mathrm{N}}^{*}$ more concretely, let us consider tests of the following joint hypothesis:

\section{$H_{o}^{*}: H_{o}$ holds and the coefficients $\beta$ and $\gamma$ are constant over time.}

When $\beta$ and $\gamma$ are nonstationary over time, both $\hat{\beta}_{\mathrm{G}}$ and $\hat{\beta}_{\mathrm{W}}$ are inconsistent even though $\mathrm{H}_{\mathrm{o}}$ may hold. To incorporate this possibility, researchers may desire to test $\mathrm{H}_{\mathrm{o}}^{*}$. For a simple test of nonstationarity, consider equation (1) with time-varying coefficients:

$$
y_{i t}=X_{i t} \beta_{t}+Z_{i} \gamma_{t}+u_{i t}=W_{i t} \delta_{t}+u_{i t} \text {. }
$$

Adding these equations over $\mathrm{t}$ (and with some algebra), we obtain: 


$$
\bar{y}_{i}=\bar{W}_{i} \bar{\delta}+\sum_{t=1}^{T} X_{i t}\left(\beta_{t}-\bar{\beta}\right) / T+\bar{u}
$$

The hypothesis $H_{0}^{*}$ implies that $\left(\beta_{\mathrm{t}}-\bar{\beta}\right)=0$ for any t. A LM statistic for the restrictions in (23) is given:

$$
L_{N}^{*}=e_{B}^{\prime} P\left(Z, S^{*}\right) e_{B} / \sigma_{B}^{2}
$$

While this statistic also has power to test $\mathrm{H}_{\mathrm{o}}$, we expect by its construction that it may be more appropriate for detecting nonstationary coefficients. ${ }^{4}$

Proposition 2 details the relationship among $\mathrm{H}_{\mathrm{N}}, \mathrm{J}_{\mathrm{N}}^{*}$ and $\mathrm{L}_{\mathrm{N}}^{*}$.

Proposition 2. $\mathrm{J}_{\mathrm{N}}^{*}=\mathrm{H}_{\mathrm{N}}+\mathrm{L}_{\mathrm{N}}^{*}$.

Proof. See appendix.

The relative power of $\mathrm{H}_{\mathrm{N}}$ and $\mathrm{L}_{\mathrm{N}}^{*}$ are likely to vary depending upon the form of model misspecification. However, Proposition 2 implies that in situations when either $\mathrm{H}_{\mathrm{N}}$ or $\mathrm{L}_{\mathrm{N}}^{*}$ has good power for detecting a particular form of misspecification, $\mathrm{J}_{\mathrm{N}}^{*}$ will also have power in this direction.

\section{Monte Carlo Simulations}

In this section we conduct Monte Carlo experiments in which we compare the relative

${ }^{4}$ As one may expect, when $\gamma$ is nonstationary but $\beta$ is constant over time, this test has no power to detect such misspecification, which is however unlikely to happen in practice. 
power of $\mathrm{H}_{\mathrm{N}}, \mathrm{J}_{\mathrm{N}}^{*}$ and $\mathrm{L}_{\mathrm{N}}^{*}$. The foundation for our Monte Carlo experiments is equation (22) with two regressors $X_{i t}$ and $Z_{i}$. For $T=3$, we set $\gamma=\beta_{1}=1$, and allow $\beta_{2}$ and $\beta_{3}$ to take different values, with their sum fixed at 2. We choose $\mathrm{N}=500$, and specify i.i.d. errors: $\alpha_{\mathrm{i}}$ $\sim \mathrm{N}(0,2)$ and $\varepsilon_{\mathrm{it}} \sim \mathrm{N}(0,1){ }^{5}$ To allow correlation between $\alpha_{\mathrm{i}}$ and the regressors, we set $\mathrm{X}_{\mathrm{it}}=$ $0.7 X_{i, t-1}+\rho_{x} \alpha_{i}+\eta_{i t}$ and $Z_{i}=X_{i 0}+\rho_{z} \alpha_{i}+\mu_{i}$, where $X_{i 0}, \eta_{i t}$ and $\mu_{i}$ are each uniformly distributed on the interval $[-2,2]$. For each value of $\rho_{x}, \rho_{z}, \beta_{2}$ and $\beta_{3}$ chosen, rejection rates for $\mathrm{H}_{\mathrm{N}}, \mathrm{J}_{\mathrm{N}}^{*}$ and $\mathrm{L}_{\mathrm{N}}^{*}$ based on 1000 replications and a 95 percent significance level are computed. All of the statistics are computed using the variance estimates given in (9). In simulations we also calculate the three statistics using an alternative representation as the product of NT and the uncentered $\mathrm{R}^{2}$. In no case does this lead to changes of rejection proportions of over $0.2 \%$ and thus these results are not reported.

\section{(Table 1 about here)}

Table 1 summarizes the results of our Monte Carlo simulations for testing $\mathrm{H}_{\mathrm{o}}^{*}$. In our base simulation with no misspecification $\left(\rho_{x}=\rho_{z}=0\right.$ and $\left.\beta_{2}=\beta_{3}=1\right)$ all test statistics perform approximately the same, with each rejecting $\mathrm{H}_{\mathrm{o}}^{*}$ in approximately $5 \%$ of the cases. Our first set of simulations allows $\rho_{\mathrm{x}} \neq 0$. We find that both $\mathrm{H}_{\mathrm{N}}$ and $\mathrm{J}_{\mathrm{N}}^{*}$ identify small degrees of correlation quite well, though $\mathrm{L}_{\mathrm{N}}^{*}$ (formulated from $\beta_{\mathrm{B}}$ ) is less successful in detecting this correlation.

5 We assign a higher value on $\operatorname{var}\left(\alpha_{\mathrm{i}}\right)$ than on $\operatorname{var}\left(\varepsilon_{\mathrm{it}}\right)$ in order to ensure that the estimate of $\theta$ is less than one for each replication. 
Our second set of simulations permits correlation between $\alpha_{i}$ and $Z_{i}\left(\rho_{z} \neq 0\right)$. We find that $\mathrm{J}_{\mathrm{N}}^{*}$ outperforms both $\mathrm{H}_{\mathrm{N}}$ and $\mathrm{L}_{\mathrm{N}}^{*}$. In contrast to the case where $\mathrm{X}_{\mathrm{it}}$ and $\alpha_{\mathrm{i}}$ are correlated, all of the tests possess relatively low power for detecting low levels of correlation, while power improves as the correlation increases. The are some intuitive reasons for this result. The Hausman test $H_{N}$ has only a limited power, because $H_{N}$ is based on the estimates of $\beta$ only, not on those of $\gamma$ (since $\gamma$ cannot be estimated by the within estimator). Thus $\mathrm{H}_{\mathrm{N}}$ can detect $\rho_{\mathrm{z}} \neq 0$ only if $\hat{\beta}_{\mathrm{G}}$ becomes substantially biased and different from $\hat{\beta}_{\mathrm{w}}$. However, low levels of correlation between $\mathrm{Z}_{\mathrm{i}}$ and $\alpha_{\mathrm{i}}$ are unlikely to cause a significant bias in $\beta_{\mathrm{G}}$. The low power of $L_{N}^{*}$ is not unexpected due to its construction. This same low power will therefore affect $\mathrm{J}_{\mathrm{N}}^{*}$, which is simply the sum of $\mathrm{H}_{\mathrm{N}}$ and $\mathrm{L}_{\mathrm{N}}^{*}$.

The third set of simulations permits nonstationary coefficients of $\beta$. We assign sequentially lower values on $\beta_{2}$ and higher values on $\beta_{3}$ so that the degree of nonstationarity increases with $\beta_{3}$. Perhaps surprisingly, $\mathrm{H}_{\mathrm{N}}$ has little power in this case, and too often accepts $\mathrm{H}_{\mathrm{o}}^{*}$. Its power improves only slowly as the degree of nonstationarity increases. Both $\mathrm{J}_{\mathrm{N}}^{*}$ and $\mathrm{L}_{\mathrm{N}}^{*}$ also lack power for low levels of nonstationarity although they dominate $\mathrm{H}_{\mathrm{N}}$, but their power improves rapidly with the degree of nonstationarity.

There are two major implications from our Monte Carlo experiments. First, $\mathrm{J}_{\mathrm{N}}^{*}$ is best able to detect misspecification from all three sources of model misspecification. In cases where the appropriate hypothesis to be tested is $\mathrm{H}_{\mathrm{o}}^{*}$, the appropriate test statistic is $\mathrm{J}_{\mathrm{N}}^{*}$. Second, consistency of the within estimator seems to be a major factor determining the power of $\mathrm{H}_{\mathrm{N}}$. The poor performance of $\mathrm{H}_{\mathrm{N}}$ in the case of nonstationarity may imply that $\mathrm{H}_{\mathrm{N}}$ is not desirable whenever the sources of model misspecification under which $\hat{\beta}_{\mathrm{w}}$ becomes 
inconsistent are questioned.

\section{Concluding Remarks}

In this paper we have reformulated the Hausman specification test for the CS-TS regression model and considered an alternative GMM test which is designed to incorporate and test both endogeneity of regressors and nonstationary coefficients. Our Monte Carlo experiments reveal that the use of the alternative test is promising.

The alternative test method we have considered could be readily extended to other models. Hausman and Taylor (1981), Amemiya and MaCurdy (1986), and Breusch, Mizon and Schmidt (1989) examine cases in which some time-varying regressors are uncorrelated with individual effects, and propose 2SLS estimation methods using these regressors as instrumental variables. The appropriateness of their methods has been typically tested by a Hausman statistic based on the difference between the 2SLS estimator and the within estimator. Our results suggest that these test outcomes should be interpreted with caution. Alternative GMM test methods could be developed to test the specification of these models for other forms of model specification. 


\section{Appendix: Proof of Proposition 2}

Consider the following auxiliary regression model:

$$
P\left(B^{*}\right) \Omega^{-1 / 2} y=P\left(B^{*}\right) \Omega^{-1 / 2} W \delta+P\left(B^{*}\right) \Omega^{-1 / 2} P_{V} X \phi+\text { error }
$$

where $\mathrm{B}^{*}=\left[\mathrm{Q}_{\mathrm{V}} \mathrm{X}, \mathrm{Z}, \mathrm{S}^{*}\right]$. Let $\xi_{\mathrm{AG}}$ be the OLS estimator from a regression of (A1) and $\xi_{\mathrm{AG}}$ be the OLS estimator under the restriction $\phi=0$. Then, it can be easily shown that:

$$
\begin{aligned}
& \hat{\xi}_{A G}=\left[\hat{\beta}_{A G}^{\prime}, \hat{\gamma}_{A G}^{\prime}, \hat{\phi}_{A G}^{\prime}\right]^{\prime}=\left[\hat{\boldsymbol{\beta}}_{W}^{\prime}, \hat{\gamma}_{B s}^{\prime}\left(\hat{\beta}_{B}-\hat{\boldsymbol{\beta}}_{W}\right)^{\prime}\right]^{\prime} \\
& \tilde{\xi}_{A G}=\left[\tilde{\beta}_{A G}^{\prime}, \tilde{\gamma}_{A G}^{\prime}, \tilde{\phi}_{A G}^{\prime}\right]^{\prime}=\left[\hat{\beta}_{G}^{\prime}, \hat{\gamma}_{G}^{\prime}, 0^{\prime}\right]^{\prime}
\end{aligned}
$$

Let $\mathrm{SSE}_{\mathrm{u}}$ and $\mathrm{SSE}_{\mathrm{r}}$ be the sums of squared residuals from the unrestricted and restricted regressions of (A1), respectively. Similarly to Proposition 1, the Wald statistic of the restriction $\phi=0$, which is constructed based on $\hat{\phi}_{\mathrm{AG}}$, must also equal the Hausman test. Therefore, we have:

$$
\left[S S E_{r}-S S E_{u}\right] / \sigma_{\epsilon}^{2}=H_{N}
$$

We complete the proof by showing that $\left(\mathrm{J}_{\mathrm{N}}^{*}-\mathrm{L}_{\mathrm{N}}^{*}\right)$ equals the left-hand side of $(\mathrm{A} 4)$. The orthogonality between $\mathrm{Q}_{\mathrm{V}} \mathrm{X}$ and $\left[\mathrm{Z}, \mathrm{S}^{*}\right]$ implies:

$$
\Omega^{-1 / 2} P\left(B^{*}\right) \Omega^{-1 / 2}=P\left(Q_{V} X\right)+\theta^{2} P\left(Z, S^{*}\right)
$$

Then, substituting (A2) and (A5) into $\mathrm{SSE}_{\mathrm{u}}$, and using the fact that $\mathrm{X}^{\prime} \mathrm{Q}_{\mathrm{V}}\left(\mathrm{y}-\mathrm{X} \hat{\beta}_{\mathrm{W}}\right)=0$, we obtain $\mathrm{L}_{\mathrm{N}}^{*}=\mathrm{SSE}_{\mathrm{u}} / \sigma_{\varepsilon}^{2}$. Similarly, we can show that $\mathrm{J}_{\mathrm{N}}^{*}=\mathrm{SSE}_{\mathrm{r}} / \sigma_{\varepsilon}^{2}$. 


\section{References}

Amemiya, T. and T.E. MaCurdy, 1986, Instrumental-variables estimation of an errorcomponents model, Econometrica 54, 869-880.

Arellano, M., 1993, On the testing of correlated effects with panel data, Journal of Econometrics 59, 87-97.

Balestra, P. and M. Nerlove, 1966, Pooling cross-section and time-series data in the estimation of a dynamic model: The demand for natural gas, Econometrica 34, 585612.

Baltagi, B. and S. Khanti-Akom, 1990, On efficient estimation with panel data: An empirical comparison of instrumental variables estimators, Journal of Applied Econometrics 5, 401-406.

Breusch, T.S., G.E. Mizon and P. Schmidt, 1989, Efficient estimation using panel data, Econometrica 57, 695-700.

Cornwell, C. and P. Rupert, 1988, Efficient estimation with panel data: An empirical comparison of instrumental variables estimators, Journal of Applied Econometrics 3, 149-155.

Hansen, P.L., 1982, Large sample properties of generalized method of moments estimators, Econometrica 50, 1029-1054.

Hausman, J.A., 1978, Specification tests in econometrics, Econometrica 46, 1251-1272.

Hausman, J.A. and W.E. Taylor, 1981, Panel data and unobservable individual effects, Econometrica 49, 1377-1398.

Mundlak, Y., 1978, On the pooling of time series and cross section data, Econometrica 46, 69-85. 
Table 1

Monte Carlo Simulations: Rejection Rates for Tests of $\mathbf{H}_{0}^{*}$

\begin{tabular}{|c|ccccc|ccc|}
\hline \hline & $\rho_{\mathrm{x}}$ & $\rho_{\mathrm{z}}$ & $\beta_{1}$ & $\beta_{2}$ & $\beta_{3}$ & $\mathrm{H}_{\mathrm{N}}$ & $\mathrm{J}_{\mathrm{N}}^{*}$ & $\mathrm{~L}_{\mathrm{N}}^{*}$ \\
\hline Base & 0.0 & 0.0 & 1.0 & 1.0 & 1.0 & 0.052 & 0.048 & 0.055 \\
\hline Vary $\rho_{\mathrm{x}}$ & 0.1 & 0.0 & 1.0 & 1.0 & 1.0 & 0.917 & 0.881 & 0.271 \\
& 0.2 & & & & & 1.000 & 1.000 & 0.737 \\
& 0.3 & & & & & 1.000 & 1.000 & 0.961 \\
& 0.4 & & & & & 1.000 & 1.000 & 0.998 \\
\hline Vary $\rho_{\mathrm{z}}$ & 0.0 & 0.1 & 1.0 & 1.0 & 1.0 & 0.089 & 0.096 & 0.073 \\
& & 0.5 & & & & 0.656 & 0.790 & 0.525 \\
& & 1.0 & & & & 0.942 & 0.990 & 0.889 \\
& & 2.0 & & & & 0.940 & 0.995 & 0.943 \\
\hline Vary $\beta_{2}$ & 0.0 & 0.0 & 1.0 & 0.9 & 1.1 & 0.059 & 0.083 & 0.077 \\
and $\beta_{3}$ & & & & 0.7 & 1.3 & 0.097 & 0.338 & 0.353 \\
& & & & 0.5 & 1.5 & 0.172 & 0.762 & 0.764 \\
& & & & 0.4 & 1.6 & 0.206 & 0.892 & 0.905 \\
& & & & 0.3 & 1.7 & 0.252 & 0.966 & 0.973 \\
& & & & 0.0 & 2.0 & 0.396 & 1.000 & 1.000 \\
\hline
\end{tabular}

